\title{
Structural and Spectroscopic Aspects of Schiff Base Metal Complexes of Cobalt(II), Nickel(II) and Copper(II)
}

\section{B.K. RAI ${ }^{\star}$, PUJA SINHA ${ }^{1}$, VINEETA SINGH ${ }^{2}$, S.N. VIDHYARTHI ${ }^{3}$, AMIT $^{3}$, ASHOK PANDEY ${ }^{4}$ and SHASHI BHUSAN SHAHI ${ }^{3}$}

\author{
*Department of Chemistry, L. N. T. College, B. R. A. Bihar University, Muzaffarpur, \\ ${ }^{1} \mathrm{~F}$ N S Academy +2 Govt. School, Guljarbagh, Patna, India. \\ ${ }^{2} B$ N R +2 Govt. School, Guljarbagh, Patna, India. \\ ${ }^{3}$ University Department of Chemistry, J. P. University, Chapra, India. \\ ${ }^{4} \mathrm{M}$. H. Degree College, Tarwara, Siwan \\ *Corresponding autho E-mail : binodkr_rai@yahoo.co.in
}

http://dx.doi.org/10.13005/ojc/300366

(Received: April 15, 2014; Accepted: May 24, 2014)

\begin{abstract}
The complexes of $\mathrm{Co}(\mathrm{II}), \mathrm{Ni}(\mathrm{II})$ and $\mathrm{Cu}(\mathrm{II})$ with Schiff base 2-butyl thioquinazoline $4(3 \mathrm{H})$ thiosemicarbazone were synthesized. The general formulae of the complexes are of the type $\left\{\mathrm{M}(\mathrm{L})_{2} \mathrm{X}_{2}\right], \mathrm{L}=2$ - butyl thioquinazoline $4(3 \mathrm{H})$ thiosemicarbazone; $\mathrm{x}=\mathrm{Cl}^{-}, \mathrm{Br}, \mathrm{I}^{-}$and $\mathrm{NO}_{3}$. Elemental analyses and spectral (IR, electronic) studies of the synthesized complexes suggest the presence of octahedral, environment around the central metal ion. These complexes were also subjected to study their antimicrobial screening against, Gram positive bacteria Candida albicans and gram negative bacteria Escherichia coli by disc diffusion technique.
\end{abstract}

Key words : Schiff bases/ BTQT / Complex / Co(II), Ni(II) and Cu(II)/ antimicrobial screening.

\section{INTRODUCTION}

Thiosemicarbazone used as suitable ligand due to variable bonding abilities and several biocidal importance such as inhibitory action antiviral, antibacterial and anti-fungal activity ${ }^{1-9}$. Based on the above biocidal importance of thiosemicarbazone and in continuation of our earlier recent work ${ }^{10-23}$ on the synthesis and characterization of Schiff base metal complexes with nitrogen and sulphur containing
Schiff base, we report here the synthesis and antimicrobial evaluation of complexes of $\mathrm{Co}(\mathrm{II}), \mathrm{Ni}(\mathrm{II})$ and $\mathrm{Cu}(\mathrm{II})$ with the ligand, 2 butyl-thioquinazoline $4(3 \mathrm{H})$ thiosemicarbozone.

\section{EXPERIMENTAL}

The chemical and reagent were used as obtained from commercial supplies without further purification. The analysis of carbon, hydrogen and 
nitrogen as well as metal ions were performed using standard procedure ${ }^{24}$. IR spectra were recorded in $\mathrm{KBr}$ pellets in $4000-200 \mathrm{~cm}^{-1}$ region on Perkin Elmer-577 spectrophotometer. Electronic spectra were recorded on Cary-2390 spectrophotometer in the $10000-25000 \mathrm{~cm}^{-1}$. Magnetic susceptibility of the complexes were done on a Gouy balance using $\mathrm{Hg}\left[\mathrm{Co}(\mathrm{NCS})_{4}\right]$ as a calibrant. Molar conductivity of the Complexes were done at room temperature on Systronics conductivity meter model 303 using DMF as a solvent. Antimicrobial activity of the ligand and the complexes was carried out against E. coli and S. aureus by disc diffusion method.

\section{Preparation of the ligand}

A solution of thiosemicarbazide $(0.01$ $\mathrm{mol})$ in $25 \mathrm{ml}$ in ethanol was added to 2-butyl thioquinazoline $4(3 \mathrm{H})$ one $(0.01 \mathrm{~m})$ dissolved in ethanol $(25 \mathrm{ml})$ with occasional stirring. The reaction mixture was heated under reflux on a water bath for $4 \mathrm{~h}$. After reducing the solvent volume to $\mathrm{Ca} .30 \mathrm{ml}$ and cooling to room temperature, the colourless solid obtained was filtered, washed with ethanol and dried in a oven. Yield- $70 \%$ m.p. $-316^{\circ} \mathrm{C} \pm 1^{\circ} \mathrm{C}$

\section{Synthesis of complexes}

The complexes were prepared by reating appropriate metal halide/nitrate with the ethanolic solution of the ligand in molar ratio 1:2. The resulting mixture was refluxed for 3-4 $\mathrm{h}$. On cooling to room temperature the coloured complexes were precipitated out. It was filtered, washed with hot water, ethanol and finally dried in oven yield $60-65 \%$.

\section{RESULTS AND DISCUSSION}

In order to give conclusive evidence about the structure of the metal complexes, the main IR bands of the metal complexes, the main IR bands were compared with those of the free ligands. The IR spectra of the free ligand shows a medium band at $1570 \mathrm{~cm}^{-1}$ shifting towards lower wave number is due to the coordination of azomethine nitrogen with metal ion. The proposed linkage with azomethine nitrogen with metal ions are further supported by the appearance of a band in for IR region at $435-460 \mathrm{~cm}^{-1}$ in the complexes assigned ${ }^{26,27}$ to $\mathrm{v}_{\mathrm{M}-\mathrm{N}}$. The $>\mathrm{C}=\mathrm{S}$ band appearing at $840 \mathrm{~cm}^{-1}$ in IR spectrum of ligand is shifted towards lower wave number in the spectra of the complex. This is due to coordination of thione sulphur ${ }^{28}$ atom to metal ions. The linkage with metal ion with thione sulphur atom is further supported by the appearance of a band in far IR region at 395-410 $\mathrm{cm}^{-1}$ assigned ${ }^{26,27}$ to $v_{\mathrm{M}-\mathrm{s}}$. The Coordination through halogen atoms are indicated by the appearance of a band in far IR region at $315-260 \mathrm{~cm}^{-1}$ assigned 26,27 to $v_{\mathrm{M}-\mathrm{X}}(\mathrm{x}=\mathrm{Cl}, \mathrm{Br}, \mathrm{l})$. The coordination with halogen is supported by the low molar conductivity of the complexes in the range 8.9-14.3 $\mathrm{ohm}^{-1} \mathrm{~cm}^{2} \mathrm{~mol}^{-1}$. The band at $1320 \mathrm{~cm}^{-1}$ and $1440 \mathrm{~cm}^{-1}$ indicates mono-coordinate linkage of nitrate groups with metal ions. Linkage with oxygen atom of nitrate group is support by appearance of a far IR band at 545-515 $\mathrm{cm}^{-1}$ assigned to $v_{\mathrm{M}-\mathrm{O}}$.

On the basis of IR spectral positions it may be proposed that ligand BTQT, acts as neutral

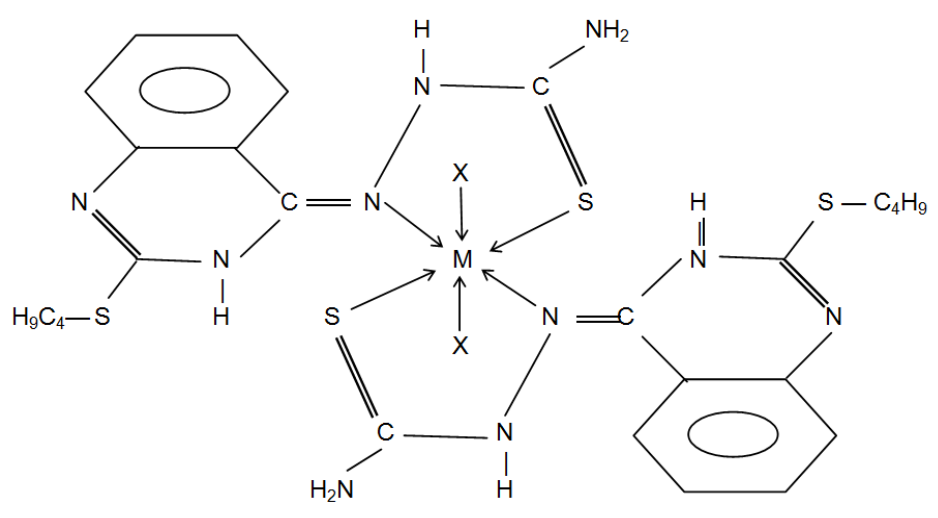

Fig. 1 : [M(BTQT) $\left.{ }_{2}\right]$

$\mathrm{M}=\mathrm{Co}(\mathrm{II})$ and $\mathrm{Ni}(\mathrm{II}) ; \mathrm{X}=\mathrm{Cl}, \mathrm{Br}, \mathrm{I}$ or $\mathrm{NO}_{3}$. $\mathrm{M}=\mathrm{Cu}(\mathrm{II}) ; \mathrm{X}=\mathrm{Cl}$, $\mathrm{Br}$ or $\mathrm{NO}_{3}$. 


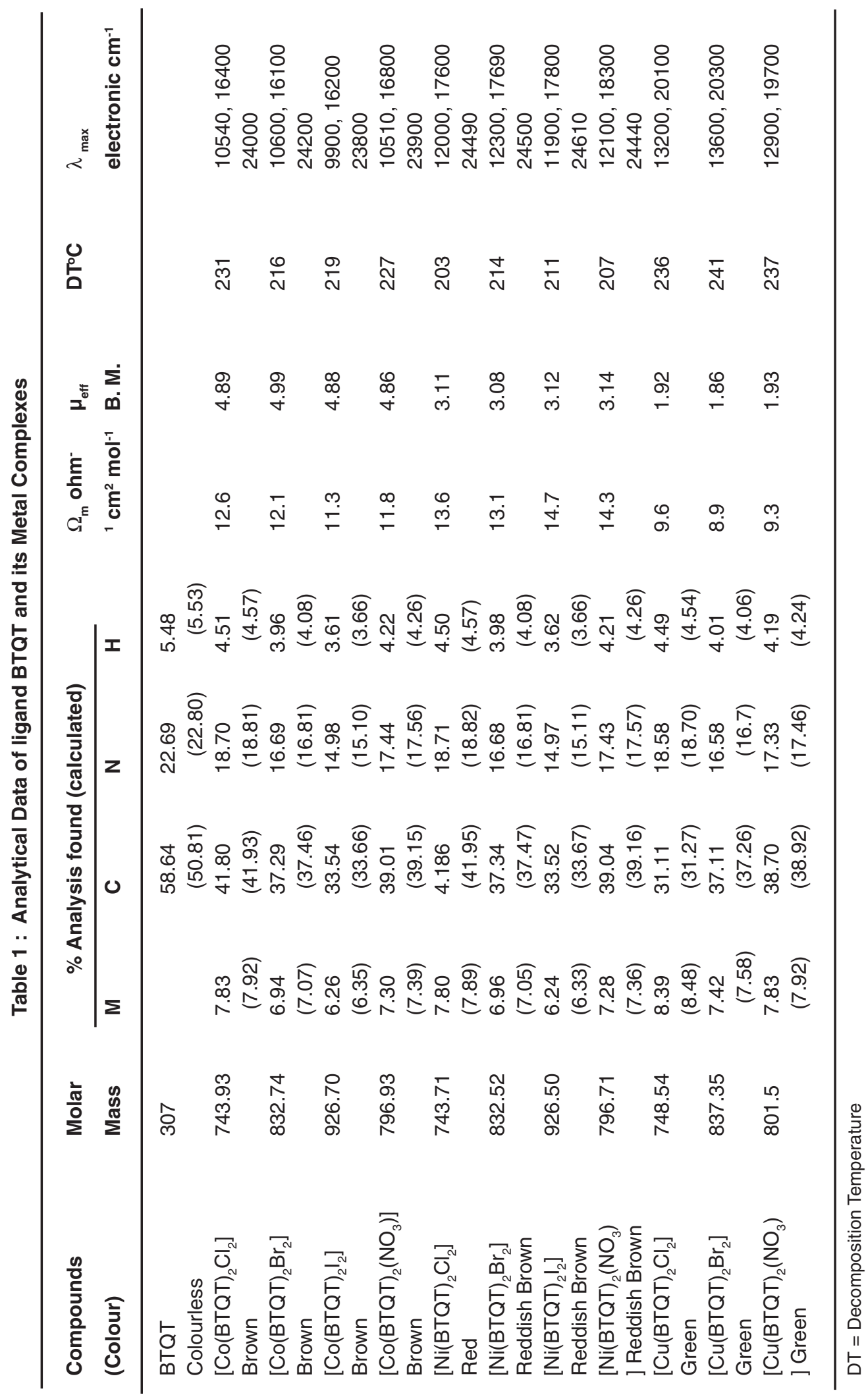


bidentate ligand. Coordination proposes through azomethine nitrogen and thione sulphur to the metal ion. The remaining coordination centers are satisfied by negative ions such as $\mathrm{Cl}^{-}, \mathrm{Br}$, I- or $\mathrm{NO}_{3}^{-}$.

\section{Magnetic susceptibility electronic spectra}

The electronic spectra of the Co(II) complexes exhibit three bands in the region 10600$9900 \mathrm{~cm}^{-1} 16800-16100 \mathrm{~cm}^{-1}$ and $24200-23800 \mathrm{~cm}^{-1}$ assigned to ${ }^{4} \mathrm{~T}_{1 \mathrm{~g}}(\mathrm{~F}) \rightarrow{ }^{4} \mathrm{~T}_{2 \mathrm{~g}}(\mathrm{~F}),{ }^{4} \mathrm{~T}_{1 \mathrm{~g}}(\mathrm{~F}) \rightarrow{ }^{4} \mathrm{~A}_{2 \mathrm{~g}}(\mathrm{~F})$ and ${ }^{4} \mathrm{~T}_{1 \mathrm{~g}}(\mathrm{~F}){ }^{4} \mathrm{~T}_{1 \mathrm{~g}}(\mathrm{P})$ respectively suggesting ${ }^{29}$ an octahedral geometry of $\mathrm{Co}$ (II) complexes. The proposed geometry is further supported ${ }^{30,31}$ by the magnetic moment value in the range 4.86-4.99 BM.

The electronic spectra of $\mathrm{Ni}(\mathrm{II})$ complexes exhibit three bands in the region $11800-12300 \mathrm{~cm}^{-1}$ strong intense band in the vicinity of $24500 \mathrm{~cm}^{-1}$ assignable due to the transitions, ${ }^{3} \mathrm{~A}_{2 g}(F) \rightarrow{ }^{3} \mathrm{~T}_{2 g}(F)$, ${ }^{3} A_{2 g}(F) \rightarrow{ }^{3} T_{1 g}(F)$ and ${ }^{3} A_{2 g}(F) \rightarrow{ }^{3} A_{2 g}(P)$ respectively. These positions propose ${ }^{29}$ an octahedral geometry for $\mathrm{Ni}(\mathrm{II})$ complexes which is further supported ${ }^{30,31}$ by the magnetic moment of value of $\mathrm{Ni}(\mathrm{II})$ complexes in the range 3.08-3.14 B.M. The electronic spectra pf $\mathrm{Cu}$ (II) complexes exhibit two spectral bands in the region $12900-13600 \mathrm{~cm}^{-1}$ and $19700-20300$ $\mathrm{cm}^{-1}$ assigned to the transitions, ${ }^{2} \mathrm{E}_{\mathrm{g}} \rightarrow{ }^{2} \mathrm{~T}_{2 \mathrm{~g}}$ and charge transfer band. The magnetic moment value of $\mathrm{Cu}$ (II) complexes lie In the range of 1.86-1.93 B.M. The above data of electronic spectra suggested an octahedral geometry for $\mathrm{Cu}(\mathrm{II})$ complexes.

\section{Molar conductance}

Molar conductance of the complexes were measured in DMF at the concentration $10^{-3}$ and all the complexes were found to be non-electrolytic in nature due to $10 \mathrm{~W}$ value of molar conductance in the range 8.9-14.3 $\mathrm{ohm}^{-1} \mathrm{~cm}^{2} \mathrm{~mol}^{-1}$.

\section{Antimicrobial Screening}

Antibacterial activity of Schiff base ligand, BTQT and its Cobalt, Nickel and Copper complexes

Table-2 : Infra Red spectral data of the ligand and complexes

\begin{tabular}{lccccc}
\hline Compounds & $v_{\mathrm{C}=\mathrm{O}}$ & $v_{\mathrm{C}=\mathrm{N}}$ & $v_{\mathrm{M}-\mathrm{O}}$ & $v_{\mathrm{M}-\mathrm{N}}$ & $v_{\mathrm{M}-\mathrm{x}}$ \\
\hline $\mathrm{BTQT}$ & 1570 & 840 & & & 260 \\
{$\left[\mathrm{Co}(\mathrm{BTQT})_{2} \mathrm{Cl}_{2}\right]$} & 1550 & 810 & 450 & 410 & \\
{$\left[\mathrm{Co}(\mathrm{BTQT})_{2} \mathrm{Br}_{2}\right]$} & 1550 & 820 & 440 & 405 & 270 \\
{$\left[\mathrm{Co}(\mathrm{BTQT})_{2} \mathrm{I}_{2}\right]$} & 1545 & 805 & 455 & 400 & 280 \\
{$\left[\mathrm{Co}(\mathrm{BTQT})_{2}\left(\mathrm{NO}_{3}\right)\right]$} & 1540 & 810 & 460 & 405 & \\
{$\left[\mathrm{Ni}(\mathrm{BTQT})_{2} \mathrm{Cl}_{2}\right]$} & 1550 & 820 & 440 & 395 & 295 \\
{$\left[\mathrm{Ni}(\mathrm{BTQT})_{2} \mathrm{Br}_{2}\right]$} & 1545 & 810 & 435 & 400 & 305 \\
{$\left[\mathrm{Ni}(\mathrm{BTQT})_{2} \mathrm{I}_{2}\right]$} & 1540 & 810 & 435 & 405 & 315 \\
{$\left[\mathrm{Ni}(\mathrm{BTQT})_{2}\left(\mathrm{NO}_{3}\right)\right]$} & 1545 & 820 & 440 & 405 & \\
{$\left[\mathrm{Cu}(\mathrm{BTQT})_{2} \mathrm{Cl}_{2}\right]$} & 1550 & 820 & 460 & 400 & 285 \\
{$\left[\mathrm{Cu}(\mathrm{BTQT})_{2} \mathrm{Br}_{2}\right]$} & 1540 & 810 & 455 & 395 & 290 \\
{$\left[\mathrm{Ni}(\mathrm{BTQT})_{2}\left(\mathrm{NO}_{3}\right)\right]$} & 1540 & 810 & 440 & 395 & 300 \\
& & & & & \\
\hline
\end{tabular}

have been tested by disc diffusion technique ${ }^{33}$. The Gram positive and Gram negative organism such Gram negative bacterial E. Coli and Gram Positive bacteria Candida albicans were used to find out the antimicrobial activity. All the complexes showed a remarkable antimicrobial activity against bacteria. From the results it is proposed that the metal complexes are found to have more biocidal activity than the parent ligand.

\section{CONCLUSIONS}

The IR spectral studies revealed that the ligand, BTQT acted as a neutral bidentate(NS donor) in all the complexes. The magnetic conductance and electronic spectral studies reveal the complexes were paramagnetic with octahedral geometries. The remaining valency are satisfied by negative ions such as $\mathrm{Cl}^{-}, \mathrm{Br}, \mathrm{l}^{-}$or $\mathrm{NO}_{3}$. All investigated complexes were non-electrolytic in nature as given in Fig.-1. 


\section{REFERENCES}

1. Abbert A. and Barlin G.B., J. Chem., Soc; 1962, 3129.

2. Ghorab M.M., El-Sayed B.S., Saker H.M. and Rabo M. Abd, Arzneimittelforsc, 2006, 56, 665.

3. Jessy E.M., Vachala D., Navneet K. and Srinivassan, Pharacology online, 2008, 2, 618.

4. Gupta V. kashaw S.K., jatav V. and Mishra Med. Chem. Res; 2008, 17, 205.

5. Hamed M.S., Kamel M.M., Kaseem M.M., Notal M.S. and Ahmed F.M. Acta Poloniae Pharmaceutica-Drug Res. 2010, 67, 159.

6. Al-obaid M., Abdel-Hameid S.G., El-kashet H.A., Abdul Aziz A.A.M., El-Azab A.S., alKhamees M.A. and El-Subbagh H.I., Euro J. Med. Chem; 2009, 44, 2379.

7. Al Omar M.A., El-Azab A.S., El-Obeid H.A. and Abdul Hameide S.G., J. Saudi Chem; Soc; 2006, 10, 113.

8. Kumar A. Sharma s., archana Bajaj K., Sharma S. Panwar H., Singh T and Srivastav V.K., Biooir.Med. Chem., 2003, 11, 5293.

9. Lu C., Yang J., Chiang J., Hour M, Lin K., Lin J., Huang W., Tsuzuki M., Leel T. and Chung J., Plosone, 2012, 7, 1.

10. Rai B.K., Sinha Puja, Vidhyarthi S.N. and Singh Vineeta, Asian J. Chem., 2011, 23, 4629.

11. Rai B.K., Singh Vineeta, Vidhyarthi S.N. and Sinha Puja, Asian J. Chem, 23, 4638.

12. Rai B.K., Sinha Puja, Vidhyarthi S.N. and Sinha Puja, Singh Kalyan Chnadra, Sahi Shashi Bhusan and Ojha Jayvir Sharan, Orient J. Chem, 2012, 28, 1365.

13. Rai B.K., Vidhyarthi S.N., Amit, Singh Rabindra, Bharadwaj Nitish and Ojha avinash, Orient J. Chem; 2012, 28, 1403.

14. Rai B.K., J. Indian Chem; Soc., 2013, 90, 105.

15. Rai B.K., Vidhyarthi S.N., Kumari Punam, Kumari sunam, Kumari Lakshmi, and Singh Rajkishore, Asian J. Chem., 2013, 25, 941.

16. Rai B.K., Vidhyarthi S.N., Singh Puja, Singh Vineeta and Kumar Snajeev, Orient J. Chem.,
2013, 29, 271.

17. Rai B.K., Kumar Sanjay, anand Rahul and Pandey ashok, Orient J. Chem, 2013, 29, 655.

18. Rai B.K., Singh Rabindra, Anand Puja, Singh Sunil, Kumar and Amit, Orient J, Chem, 2013, 20, 753.

19. Rai B.K., Vidhyarthi S.N., Prakash Om, Balunil Akhilesh, Orient J. Chem., 2013, 29, 801.

20. Choudhary Chitranjan Prasad, Sharma S.P., Rai C.L. and Rai B.K., Orient J. Chem., 2013, 29, 963.

21. Kumari Rachana and Rai B.K., Orient J. Chem, 2013, 29, 1163.

22. Rai B.K. and Kumar Arun, Orient J. Chem; 2013, 29, 1187.

23. Kumar Ajit, Yavadav U.S. and Rai B.K., Orient J. Chem., 2013, 29, 1203.

24. Vogel A.I., A Textbook of Quantitative Chemical Analysis, Revised by Besset J., Denny R.C., Jeffery J.H. and Mendham J., ELBS, $5^{\text {th }}$ Edn., London(1996); Chaube S.N., Shrivastav J.P. and Mishra L.K., Inorg. Chem., Acta, 1977, 23, 1.

25. Agarwal R.K., arora K., Polish J. Chem., 67, 219(1993).

26. Singh N.K., Shrivastav A.K., Agarwal R.C., Indian J. Chem; 1984; 22A, 704.

27. ferraro J.R., Low Frequency Vibration of Inorganic and Coordination Compounds, Plenum Press, new York.

28. Banerjee P., Singh I.P., Indian J. Chem., 1968, 6, 34.

29. Lever A.B.P., Electronic Spectroscopy, Elsevier, Amsterdam, 1968, 395.

30. Figgis B.N., Introduction to Ligand Field, Wiely Eastern Ltd., New Delhi, 1976, 279.

31. Carlin R.L., Van Dryneveldt A.J., Magnetic Properties of transition metal Compounds, Spriner Verlag, new York 1997.

32 Kettle S.F.A., Coordination Compounds, Thomas nelson and Sons, 1975, 168.

33 Mukhurjee P.K., Saha K., Giri s.N., Pal M. and Saha B.P., Indian J. Microbiology, 1995, 35. 